\title{
Fostering Critical Thinking Skills in German as Foreign Language Classroom
}

\author{
Ajeng Dianing Kartika ${ }^{1}$, Yunanfathur Rahman ${ }^{2}$, Dwi Imroatu Julaikah ${ }^{3}$ \\ 1,2,3 Universitas Negeri Surabaya, Surabaya, Indonesia, \\ (*) $\square$ ajengkartika@unesa.ac.id
}

\begin{abstract}
Thinking is an innate human beings capacity that can be developed through learning process. Therefore there is specific purpose on learning that has to be achieved namely gradually developing thinking skills, specifically critical thinking skills. As one aspect that has to be mastered before High Order Thinking Skills (HOTS), critical thinking skills have recently emerged as a new focus in education research. In consequence these skills have to be integrated in the classroom, not least in the foreign language classroom. Classroom research has been conducted in the class Lesen II (Reading II) to enhance student's critical thinking skills using problem-based learning. Reading involves specific thinking process to gain comprehensive understanding. The data were collected through observations, interviews, and document. The findings suggest that the development of critical thinking skills using problem-based learning in the Lesen II classroom can be performed into two stages, i.e a) pointing controversial issues and (ii) active learning through discussion and debate. This study confirms that problem-based learning is an effective alternative to develop university student's critical thinking skills in German as foreign language classroom, in the subject Lesen II.
\end{abstract}

Keywords: critical thinking skills, reading comprehension, german as foreign language

\section{Introduction}

As stated by Kartika (2018) learning priority in the $21^{\text {st }}$ century focuses on how the students develop their ability on 4 aspects, specifically conceptual understanding, critical thinking, collaboration and communication, and creative thinking. Critical thinking ability becomes one significant aspects to be mastered by students in this era, where informations can be easily accesed and spreaded. We can observe the convenience of the students to access the internet and get informations quickly by typing their keywords of the informations they can directly obtain these from various sources (Lipmann, 2003). In this case the students should be able to filter and utilize informations. Therefore it's important for them to have critical thinking ability. This ability is also an importatnt part mentioned in Indonesian national education purpose. 
There are many definitions of critical thinking that stated by the experts. Critical thinking is the ability and willingness to assess claims and make objective judgments on the basis of well-supported reasons and evidence rather than emotion or anecdote. (Wade and Tavris, 2008). Bassham, Irwin, Nardone \& Wallace (2011) consider critical thinking as a wide range of cognitive skills and intellectual dispositions to analyze arguments and overcome prejudices, respectively Astleitner (2007) defines it as a high order thinking skill at assessing arguments which involves interpretation, analysis, evaluation, and inference. From all those definitions it can be simply concluded that critical thinking is the high order thinking skill that able people not only to understand the event or information, but also being able to analyse it objectively. So it is no controversy that critical thinking is central to education, moreover on higher level of education.

Critical thinking in the context of foreign language education concerns language activities that encourage students to interpret, collaborate in practicing the use of foreign languages, using internal conventions of writing ability, apply cultural knowledge, solve problems about the topic being discussed, reflecting language usage and creating discourse (Kern, 2011). In the same context in Indonesia, teachers face nowadays a great task to activate students' critical thinking ability. Referring to the survey organized PIRLS (Progress in International Reading Literacy Study) in 2006, Indonesian students occupying the lowest level in East Asia in reading skills the average literacy score is below the world average. Of the 50 countries surveyed, Indonesia is ranked 45 . Students are only able to understand $30 \%$ of the content reading so that it is difficult to answer questions of understanding and reasoning (Hayat \& Yusuf, 2010).

In reading ability, Indonesia belongs to the group Intermediate International Benchmark where the reading process is for conclusions much higher than reading indicators to interpret and integrate idea. Uniquely even though the hours of language and reading lessons are the most many, this is precisely inversely proportional to reading achievement. That is, more and more additional lessons are increasingly ineffective for develop the ability to read it. After further investigation, this too as a small impact the percentage of teachers with a language education background (11\%) and linguistics (13\%) (Hayat \& Yusuf, 2010). To fix this case critical thinking ability must be integrated in the classroom, in order to develop student's ability to understand texts.

Event though there's still debated by some experts about the term "teaching critical thinking skill" in foreign language classroom, Recent studies on the integration of critical thinking with language skills indicated significant increase of reading and writing skills when critical thinking skills are inclusively integrated in the teaching and learning process (Crook, 2006; Scanlan, 2006). As for a number of studies although it does not directly teach critical thinking techniques demonstrate improvement in critical thinking skills through application some foreign language teaching strategies (Al-Fadhli \& Khalfan, 2009; Crook, 2006; Ernst \& Monroe, 2004; Sellnow \& Ahlfeldt, 2005). Overall results the research strengthens the empirical foundation of the importance of integration thinking critical and language learning. On the basis of such incorporation, this paper will elaborate a suitable reading strategy in the classroom, which relate the reading skills with critical thinking skills.

\section{Method}

The participants are 20 students in the classroom Lesen II, who have been for a year studying German. The participants consisted of both male and female students . They are representative sample for this study because they are still on early stage of learning and fostering critical thinking ability can ease them to understand the texts, especially the cultural contexts that are integrated in the text being studied based on the purpose of the subject stated in the curriculum.

Goethe Zertikat A2 tests are used as the main instrument for conducting this research. Beside that, various texts in level A2 are considered as supporting elements. This used a qualitative study and some of the analysis was done by literature analysis. The literature analysis was carried out to find out the reading strategy used to foster student's critical thinking ability and describing the correlation of critical thinking ability and the student's ability to understand texts. This research had been 
conducted for 6 months. Before it started pre test was given to check the student's level in reading comprehension, in order to find out the best strategy used to develop their ability. After that some strategies were applied to stimulate the students and involve them into active learning. This part enable the students to be actively involved in discussion, presentation, and debate to gain the whole meaning of the texts and set their point of view.

The strategy used in this research to foster students critical thinking skills is critical reading strategy. Reading is an interactive process between the text and the reader to co-construct meaning. A student's schemata consists of their existing concepts about the world, or "knowledge already stored in memory" (Anderson and Pearson, in Larking 2017). Comprehending texts requires more than just linguistic knowledge. Experience and culture shape readers' schemata and L1 can also influence their understanding and interpretation of English passages (Mikulecky, 2008). Every culture provides a different schemata of the world and lectures need to be equipped with the skills necessary to help students with varying world views. Learning to read in a foreign language entails dealing with different text types and entertaining different cultural beliefs. It involves changing the reader's values and cognitive processing, potentially modifying one's schemata (Larking, 2017). Therefore critical reading strategy become the right strategy applied in this research.

Critical reading is an investigation into, and critique of the validity of arguments expressed in reading passages (Walz, 2001). Underlying meanings are enmeshed within the surface, or facevalue meaning of a text, which can seek to persuade the reader, sometimes with biased views, imbalanced presentation of evidence, or even purposefully including factual inaccuracies. It is the task of a critical reader to 'read between the lines' and undertake an analysis of a text to comprehensively grasp its full meaning. The term critical reading has multifarious meanings, but it can be broadly split into two distinct traditions; reading for academic success and reading for social engagement. According to Manarin, Carey, Rathburn, and Ryland (2015:4) reading critically consists of the following skills, namely :

1. Identifying patterns of textual elements

2. Distinguishing between main and subordinate ideas

3. Evaluating credibility

4. Making judgments about how a text is argued

5. Making relevant inferences about the tex

Those five skills have similiarity with the skills that have to be mastered in critical thinking, i.e. analyzing, evaluating, inferencing, interpreting, and explaining.

The choice of strategy used based the pre test score. In term of this strategy usage on Cognitive Psychology aspects that has shown the students who are consciously aware of what they are doing learn new thinking processes and strategies the most effectively. Such learners are aware of their comprehension and can apply the most appropriate strategies when comprehending a text. Instructors need to make their learners consciously aware of the reading strategies they are employing in the classroom to increase the likelihood of strategy retention (Larking, 2017). In this research the critical reading strategy from Block (1986) will be applied. He concluded their strategies could be divided into two broad types; general and local. General strategies refer to overall comprehension and include 1) anticipating content, 2) recognizing text structure, 3) question information in the text, 4) interpret the text, 5) use general knowledge and associations, 6) comment on behavior or processes, 7) monitor comprehension, 8) correct behavior, 9) react to the text These all general strategies can be well realized through local strategies include : 1)paraphrase, 2) reread, 3) question meaning of a clause or sentence, 4) question meaning of a word, 5) solve vocabulary problem. 


\section{Results and Discussion}

Cognitive skills are the primary domain of reading activities. The skills of analyzing, inferring and interpreting a text activate cognitive skills which become the major elements of critical thinking. Ellis (2008) uses a model of critical thinking rooted from Bloom's taxonomy of cognitive skills including things like logic, analysis, evaluation, inference, interpretation, explanation, and synthesis. Alternatively, some other list that decomposes these into further more specific skills could also be used. That means in this case the students have to be able not only knowing what the texts are all about, but also analysing, evaluating, inferencing, interpreting, and explaining why that kind of texts exist. For instance, analysis can be decomposed into deconstructing, contrasting, and comparing.

First, to clarify the correlation between critical thinking and reading comprehension, WatsonGlaser Critical Thinking Appraisal required a higher order thinking and relate it the criteria of a proficient reader (Brassell and Rasinski, 2008). They stated that a proficient reader has to be able and competent in reading comprehension skill. This table below will show the similarity of these and how the components interconnected.

Table 1. The Relationships Between Critical Thinking and Reading Compeherension (Brassell and Rasinski, 2008: 108)

\begin{tabular}{|c|c|}
\hline $\begin{array}{c}\begin{array}{c}\text { Characteristics of being critical thinking } \\
\text { reader }\end{array} \\
\text {. }\end{array}$ & Charachteristics of being competent reader \\
\hline $\begin{array}{c}\text { Could draw inferences based on factual } \\
\text { statement }\end{array}$ & $\begin{array}{c}\text { Could do some series of activities while reading } \\
\text { starting from asking questions about the text } \\
\text { before, during, and after reading, }\end{array}$ \\
\hline $\begin{array}{c}\text { Could recognize assumptions in a number of } \\
\text { assertive statements }\end{array}$ & Could draw inferences from the text \\
\hline $\begin{array}{l}\text { Could make deductions: to conclusions } \\
\text { information given in statements, }\end{array}$ & Could monitor his/her comprehension, \\
\hline $\begin{array}{l}\text { Could interpret evidence to decide if } \\
\text { conclusions are legitimate or not, }\end{array}$ & $\begin{array}{c}\text { Could use 'fix-up' strategies when meaning } \\
\text { breaks down, }\end{array}$ \\
\hline $\begin{array}{c}\text { Could evaluate arguments as being strong or } \\
\text { weak. }\end{array}$ & $\begin{array}{l}\text { Could figure out what is most important in } \\
\text { whatever they read and synthesize new } \\
\text { information to create new thinking. }\end{array}$ \\
\hline
\end{tabular}

Critical thinking and reading comprehension can't be separated. When people read there is cognitive proccess which requires critical thinking aspects. So both must be brought together in teaching practices to help the students developing their reading skill.

Unfortunately the pre test A2 reading score shows that there are $80 \%$ of the students get low score , that means they can't pass reading test, $7 \%$ of them get average score, and $13 \%$ get very high score. The whole score of reading test is 75 ( 0 mistake). The pre test result can be seen below.

Table 2. Pre Test Reading Section A2

\begin{tabular}{cc}
\hline Student's Reading Score & Number of The Students \\
\hline $\mathbf{1 - 1 5}$ & 3 \\
$\mathbf{1 5 - 3 0}$ & 7 \\
$\mathbf{3 0 - 4 5}$ & 4 \\
$\mathbf{4 5 - 6 0}$ & 2 \\
$\mathbf{6 0 - 7 5}$ & 4 \\
\hline
\end{tabular}

Reading section in A2 test consist of 4 parts. Each parts need a specific strategy to be applied, so the students can get the best answer. Most of the students have difficulties in the 1st and 3rd parts, which are multiple choice tasks. The other parts, 2nd and 4th parts can be answered well by them. 
The result of pre test is considered as the core of the treatment given to the students in the class Lesen II. The treatment involves several texts in level A2 taken from books (Netzwerk, Studio D A2, Tangram II, and Schritte Plus A2) and also downloaded texts from online learning resources. The treatments are held 10 times as follow : 
Table 3. Treatments Material

\begin{tabular}{|c|c|c|}
\hline Meetings & Purpose & Task \\
\hline $1-2$ & $\begin{array}{l}\text { The students are able to find main idea } \\
\text { of the text }\end{array}$ & $\begin{array}{l}\text { Read the text and find main ideas of } \\
\text { every paragraph }\end{array}$ \\
\hline 3-4 & $\begin{array}{l}\text { The students are able to arrange } 5 \mathrm{~W}+ \\
1 \mathrm{H} \text { questions from the text }\end{array}$ & $\begin{array}{l}\text { Read the text, make questions, and } \\
\text { exchange it with other friends and } \\
\text { answer the questions }\end{array}$ \\
\hline 4-5 & $\begin{array}{l}\text { The students are able to interpret the } \\
\text { text }\end{array}$ & $\begin{array}{l}\text { Read the text and interpret it verbally } \\
\text { and in writing }\end{array}$ \\
\hline $5-6$ & $\begin{array}{l}\text { The students are able to rewrite the } \\
\text { text based on their comprehension }\end{array}$ & $\begin{array}{l}\text { Read and rewrite the text given by the } \\
\text { lecture }\end{array}$ \\
\hline 6-7 & $\begin{array}{l}\text { The students are able to evaluate text } \\
\text { based on their point of view }\end{array}$ & $\begin{array}{l}\text { Evaluate the text, state their opinion } \\
\text { and give reasons for every opinion, } \\
\text { compare the text with the reality } \\
\text { surround them }\end{array}$ \\
\hline $7-8$ & $\begin{array}{l}\text { The students are able to make a } \\
\text { conclusion of the text }\end{array}$ & $\begin{array}{l}\text { Read and conclude the text, present it } \\
\text { in the small group }\end{array}$ \\
\hline $8-10$ & $\begin{array}{l}\text { The students are able to synthesize the } \\
\text { texts }\end{array}$ & Read texts and synthesize it \\
\hline
\end{tabular}

Understanding how different cultures create and interpret texts is another element in reading more critically for both students and lectures alike. This is another problem that have to be solve in the class Lesen II. The lectures have to improve their knowledge first before they teacht their students to do so. Intertextuality and the awareness of the culture are integrated in the treatments process. This step is realized by the students ability to compare the text and their experiences, also reasoning the difference happened based on the culture. After finishing treatments in the class Lesen II, the students have to take post test. The same material Goethe Zertifikat A2 was given to them. The result of the post test shows that there is an increase of the student's score. $7 \%$ of them get average score, $60 \%$ get high score, and $33 \%$ of them still have low score.

Table 4. Post Test Reading Section A2

\begin{tabular}{ll}
\hline Student's Reading Score & Number of The Students \\
\hline $\mathbf{1 - 1 5}$ & 1 \\
$\mathbf{1 5 - 3 0}$ & 3 \\
$\mathbf{3 0 - 4 5}$ & 2 \\
$\mathbf{4 5 - 6 0}$ & 2 \\
$\mathbf{6 0 - 7 5}$ & 12 \\
\hline
\end{tabular}

The 1st and 3rd part of the test, which previously in pre test had been the most difficult test to be answered experience changes in the post test. There are $55 \%$ students can answer those better and make only 1-3 mistakes compared to the pre test in which 70\% students can answer only 1-5 questions correctly.

\section{Conclusions}

To sum up, this paper showed that there is a positive relationship between critical thinking and reading comprehension ability in the class Lesen II. The students critical thinking ability can support their ability of reading. The critical reading strategy apllied in the class Lesen II affects student's reading score. Not only the score, this strategy can also foster their critical thinking ability and their awareness of what is inside the text they read and compare it with their experience. Fostering critical 
thinking in foreign language classroom, specifically in reading comprehension, is not only about finding the suitable strategy to understand the whole text, it's more about developing students knowledge and awakening their awareness of cultural differences that affect the process of comprehension. Finally it can be concluded that fostering critical thinking in reading comprehension is teaching the students how they process the texts critically until they can understand the meaning and the purpose of the whole texts. In this paper it can be proven that critical thinking can increase the test score on the reading section of Goethe Zertifikat A2 test. Furthermore this research must be continued in a broader population within different aspects, namely on writing to to explore the influence of critical thinking on students' writing skill.

\section{Acknowledgments}

The authors want to thank all lectures in German Department for the support and also Universitas Negeri Surabaya for the financial support.

\section{References}

Bassham, Gregory et.al. (2011). Critical Thinking, A Student's Introduction $4^{\text {th }}$ Edition. New York : Mc Graw Hill

Brassell, D., \& Rasinski, T. (2008). Comprehension that Works. California, USA: Shell Education

Kartika, Ajeng Dianing. (2018). Enhancing Student's Critical Thinking Through Investigation Multiliteracies Model in Contrastive Cultural Studies Clasroom. Presented in AISOFOLL held by Seameo Qitep in Language.

Larking, Malcolm. (2017). Critical Reading Strategies in the Advanced English Classroom. In APU Journal of Language Research Vol.2, 2017

Lipmann, Matthew. (2003).Thinking in Education. England: Cambridge University Press.

Manarin, K., Carey, M., Rathburn, M., \& Ryland, G. (2015). Critical Reading in Higher Education: Academic Goals and Social Engagement. Bloomington : Indiana University Press.

Mikulecky, B. S. (2008). Teaching Reading in a Second Language. http://www.longmanhomeusa.com/content/FINAL-LO\%20RES-Mikulecky reading\%20Monograph\%20.pdf. (downloaded, 1 st March 2019)

Walz, J. (2001). Critical Reading and The Internet. In Journal The French Review, volume 74 (4th edition), p.1193-1205. 